\title{
Presence of the Caenorhabditis elegans spliced leader on different mRNAs and in different genera of nematodes
}

\author{
Susan Bektesh, Kevin Van Doren, and David Hirsh \\ Synergen Inc., Boulder, Colorado 80301 USA
}

\begin{abstract}
Several different mRNAs from Caenorhabditis elegans contain the same 22-nucleotide leader sequence at their 5 ' ends that is acquired in a trans-splicing reaction. About 10 to $15 \%$ of the major proteins are translated from mRNAs that contain the spliced leader, among them two ribosomal proteins, ubiquitin, GAPDH, a heat shock protein (hsp70a), and three actins. The same spliced leader sequence is present in mRNAs isolated from nematodes from several different genera; but it is not present in mRNAs from other organisms. The spliced leader is encoded as a spliced leader (SL) RNA about 100 nucleotides long. The gene for the SL RNA is located in the 5S rDNA repeat in C. elegans; however, this association with the $5 \mathrm{~S}$ repeat is not preserved in other genera. The 22-nucleotide spliced leader sequence is conserved in three genera of nematodes.
\end{abstract}

[Key Words: Caenorhabditis elegans; spliced leader; trans-splicing]

Received April 25, 1988; revised version accepted August 18, 1988.

Krause and Hirsh (1987) reported finding a common RNA leader sequence on the $5^{\prime}$ ends of three different actin mRNAs in the nematode Caenorhabditis elegans. The 22-nucleotide leader sequence is spliced onto the actin mRNAs from a separate 100 -nucleotide precursor RNA, and this 22-nucleotide sequence became known as the spliced leader (SL), and its precursor, the spliced leader RNA (SL RNA). The mechanism by which the SL is transferred onto the mRNAs appeared to be through trans-splicing because (1) the SL and actin genes are widely separated in the genome, (2) a consensus splice donor sequence is present in the SL RNA, and (3) the actin genes contain a consensus splice acceptor where the SL joins the actin mRNA. Detection of a Y-branched intermediate in the SL addition reaction is further support for a trans-splicing mechanism (Bektesh and Hirsh 1988).

Trans-splicing in C. elegans provoked special interest for several reasons: (1) It was the first discovery of transsplicing of nuclear transcripts in a multicellular eukaryote. (2) C. elegans mRNAs contain introns whereas trypanosome mRNAs do not. Therefore, C. elegans must carry out conventional cis-splicing of internal introns in its actin mRNAs as well as trans-splicing of the SL onto the $5^{\prime}$ ends of actin mRNAs. (3) Although $C$. elegans contains four actin genes, transcripts from only three receive the SL; transcripts from the fourth gene do not undergo trans-splicing. Therefore, only some members of a closely related gene family undergo transsplicing. (4) Examination of the vitellogenin and unc-54 myosin genes and their mRNAs indicate that they do not acquire the SL (Spieth et al. 1985; Krause and Hirsh 1987). Therefore, not all of the mRNAs in C. elegans undergo trans-splicing.

These observations raise questions regarding the generality of the SL. Do other mRNAs in C. elegans contain the SL or is it a peculiarity of the three actin genes in which it was originally described? Further, is the SL present in other organisms? As shown here, other mRNAs in C. elegans acquire the SL, as do mRNAs from other nematodes. Although we could not find the $C$. elegans 22-nucleotide SL sequence in RNA from other more distantly related organisms, trans-splicing may occur, but with different SL sequences.

\section{Results}

mRNAs in addition to actin contain $S L$

The possibility that mRNAs other than actins-1, -2 , and -3 contain SL derives from an earlier observation. Some RNAs of higher molecular weights hybridize to a sequence complementary to SL in a Northern blot (Krause and Hirsh 1987). However, at that time the specificity of the hybridization was not established. We show here by additional Northern blot analyses of C. elegans RNAs that other mRNAs contain SL. We used a synthetic oligodeoxynucleotide complementary to the SL sequence as the hybridization probe (Fig. 1). This oligodeoxynucleotide hybridizes to many discrete RNAs which partition preferentially to the poly $(\mathrm{A})^{+}$RNA fraction. The 


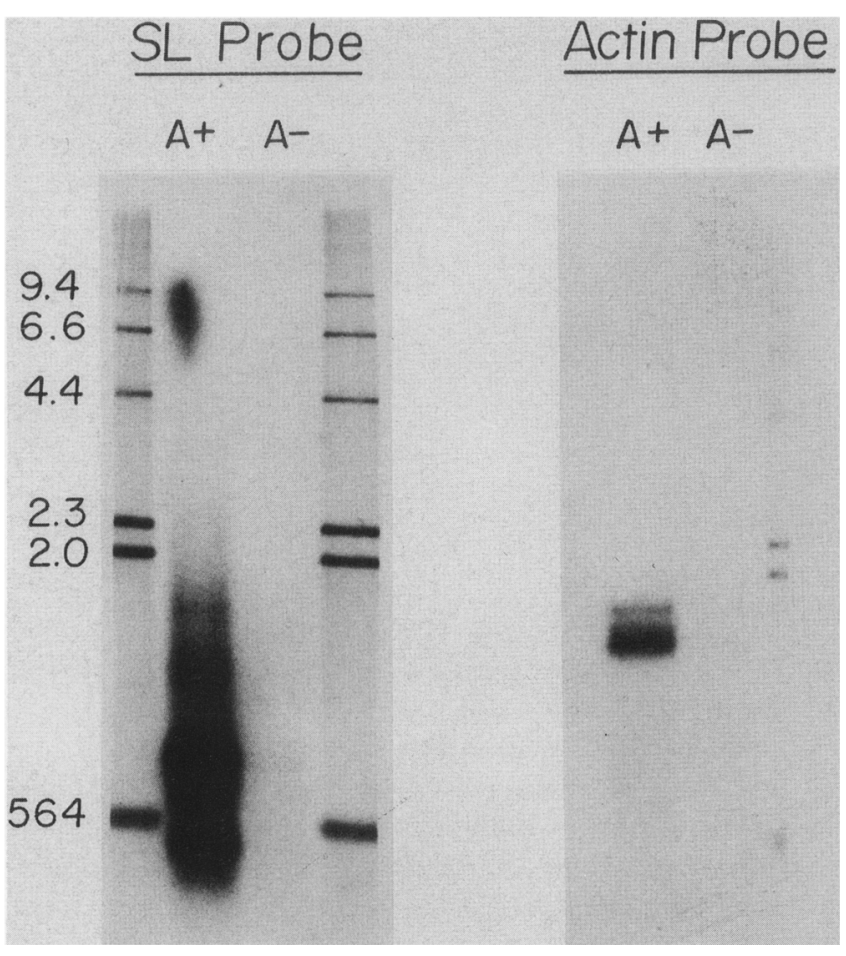

Figure 1. Analysis of $C$. elegans RNA for SL sequences. $C$. elegans RNA [Poly $(\mathrm{A})^{+}$and $\operatorname{poly}(\mathrm{A})^{-}$, as indicated] was fractionated on a $1.5 \%$ agarose-formaldehyde gel and transferred to Zetaprobe. One-half of the blot was hybridized with an oligodeoxynucleotide complementary to the SL sequence. The other half was hybridized with an oligodeoxynucleotide complementary to a portion of the actin coding sequence which is identical in all four actin genes.

most prevalent mRNA species averages about $700 \mathrm{nu}-$ cleotides. However, larger mRNAs are present, even ones larger than the actin mRNAs which are 1450, 1550, and 1650 nucleotides. The larger RNAs are not actin precursors and the smaller RNAs are not degraded actin mRNAs. This is shown by the control experiment in which an oligodeoxynucleotide complementary to actin coding sequences is used as the hybridization probe (Fig. 1). Only the expected 1450-, 1550-, and 1650-nucleotide actin mRNAs are visible.

The question arises as to how many different mRNAs contain SL. We used hybrid arrest of in vitro translation to estimate the fraction of the proteins in C. elegans encoded by mRNAs with an SL. Approximately 200 spots are distinguishable on the two-dimensional gel after the in vitro translation of $C$. elegans RNA in a rabbit reticulocyte lysate (Fig. 2A). However, 32 of these spots are either undetectable or much reduced in intensity if the RNA is first incubated with a synthetic oligodeoxynucleotide complementary to the SL (Fig. 2B).

To verify that synthetic oligodeoxynucleotides specifically inhibit translation of complementary mRNAs, RNA was transcribed in vitro from an individual SL cDNA clone, designated SL52. This cDNA clone, made from an mRNA that contains SL, was constructed as described in the next section. In vitro translation of SL52
mRNA produces a $6-\mathrm{kD}$ protein. Addition of an oligodeoxynucleotide complementary to sequences $5^{\prime}$ to the ATG initiation codon of SL52 inhibits SL52 mRNA translation as does addition of an oligodeoxynucleotide complementary to the SL (data not shown). The presence of a nonhybridizing oligodeoxynucleotide has no effect on SL52 translation.

\section{Characterizing SL cDNA clones}

To identify the individual mRNAs in addition to the actins that contain SL, we constructed a cDNA library biased for mRNAs containing SL sequences (SL mRNAs). The cDNA library was made by priming

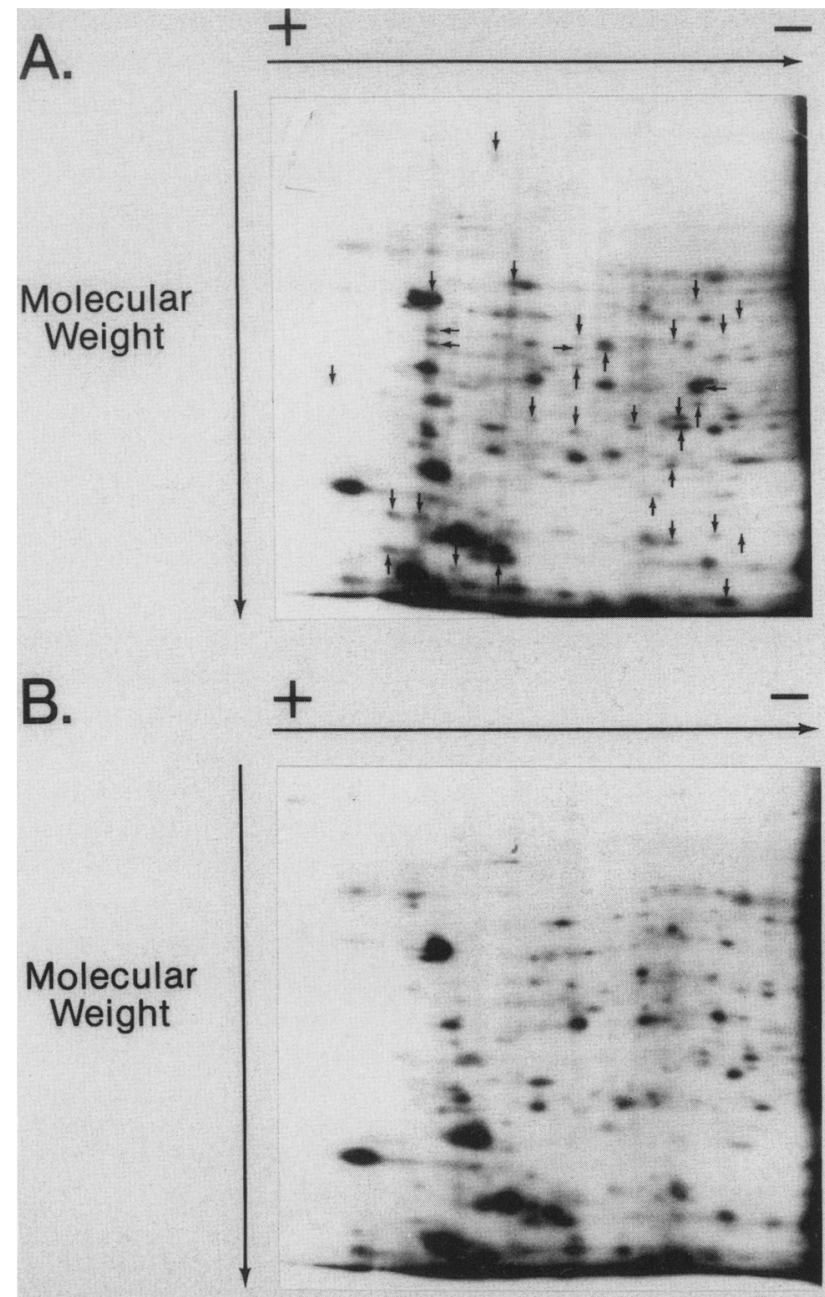

Figure 2. Hybrid arrest of in vitro translation of C. elegans RNA. Poly $(A)+$ RNA from C. elegans was translated in vitro in rabbit reticulocyte lysates containing $\left[{ }^{35} \mathrm{~S}\right]$ methionine. Labeled products were separated by two-dimensional gel electrophoresis. The products were visualized by fluorography. (A) Translation products from poly $(A)^{+}$RNA. The arrowheads indicate proteins that are absent or greatly reduced when translation is arrested using an oligodeoxynucleotide complementary to the SL. (B) Translation products from poly $(A)^{+}$RNA that was first annealed with an oligodeoxynucleotide complementary to the SL before in vitro translation. 
second-strand synthesis with a synthetic oligodeoxynucleotide with the same sequence as the SL. To characterize the SL cDNAs, 25 different SL cDNA clones were partially sequenced from both ends of the inserts, and three clones were sequenced completely (Table 1). All 25 clones have the SL at their $5^{\prime}$ ends, and the sequence is identical to the SL sequence on the $5^{\prime}$ ends of actin- $1,-2$, and -3 mRNAs (Krause and Hirsh 1987). Eight of the clones (SL118, 24, 10, 77, 57, 52, 109, 5) have a poly(A) region indicating that they are full-length cDNAs. The sequences of the SL clones show that the SL is located from 0 to 38 nucleotides upstream of the ATG; therefore, a fixed distance is not required for either the splicing or function of SLs.

We compared the sequence information from the 25 clones to the NBRF (protein) Database and determined that two clones encode known proteins. Clone SL118 is $87 \%$ homologous at the amino acid level to the yeast ribosomal protein L29; clone SL5 is $54 \%$ homologous to the rat ribosomal protein $\mathrm{L} 37$. Therefore, we believe that SL118 and SL5 encode C. elegans ribosomal proteins. Searches of the GenBank nucleic acid database did not identify any other C. elegans clone.

We wanted to be certain that SL is present on the $5^{\prime}$ ends of C. elegans ribosomal protein mRNAs, and that we were not observing nonspecific hybridization or artifacts resulting from cDNA cloning. Therefore, we carried out primer-extension sequencing of $C$. elegans mRNA using oligodeoxynucleotide primers comple-

Table 1. Characterization of SL cDNA clones

\begin{tabular}{rrlr}
\hline $\begin{array}{l}\text { Clone } \\
\text { number }\end{array}$ & $\begin{array}{c}\text { SL-ATG } \\
\text { distance }\end{array}$ & mRNA size & Known gene \\
\hline 118 & 3 & 600 & L29 yeast \\
44 & 17 & 700 & \\
10 & 1 & $1.2 \mathrm{~kb} / 5 \mathrm{~kb}$ & \\
24 & 8 & 700 & \\
31 & 6 & 800 & \\
17 & 19 & 500 & \\
15 & 13 & & \\
77 & 7 & 600 & \\
13 & 6 & 600 & \\
57 & 14 & 500 & \\
37 & 21 & 600 & \\
18 & 3 & & \\
47 & 2 & 700 & \\
52 & 38 & 350 & \\
42 & 5 & 400 & \\
109 & 2 & $600 / 900$ & \\
72 & 1 & 550 & \\
100 & 17 & & \\
64 & 15 & & \\
5 & 0 & & \\
33 & 10 & & \\
70 & 8 & & \\
27 & 0 & & \\
101 & 18 & & \\
46 & 1 & & \\
\hline
\end{tabular}

an nucleotides unless designated. mentary to sequences found in our cDNA clones. The results confirmed that the SL is present on the $5^{\prime}$ ends of the mRNAs that correspond to SL5 and SL118 (Fig. 3).

We also wanted to know if the SL cDNA clones are members of gene families and/or belong to a specific size class of mRNAs. Seventeen clones were used as hybridization probes to Northern blots and to genomic Southern blots. Although most cDNAs hybridized to RNA of 600-700 nucleotides, some hybridized to mRNAs larger than $2 \mathrm{~kb}$ (Table 1). The abundances of the mRNAs carrying SL vary depending on the particular mRNA: Clone SL13 appears to represent the most abundant SL mRNA yet observed. Most SL cDNAs hybridized to single-copy genes on genomic Southern blots; however, SL10 is a member of a large, multigene family, and SL42 is a member of a small gene family, possibly containing as few as two members.

Because only two of the 25 sequenced clones could be identified by database searches, we took another approach to identify genes whose mRNAs contain SL. If conventional cis-splicing occurs upstream of an ATG, we would expect to find splice donor sequences a short distance upstream of the acceptor sites because most $C$. elegans introns are small ( $\sim 54$ nucleotides). By contrast, if an RNA obtains SL through trans-splicing, we would expect to find an acceptor sequence upstream of the

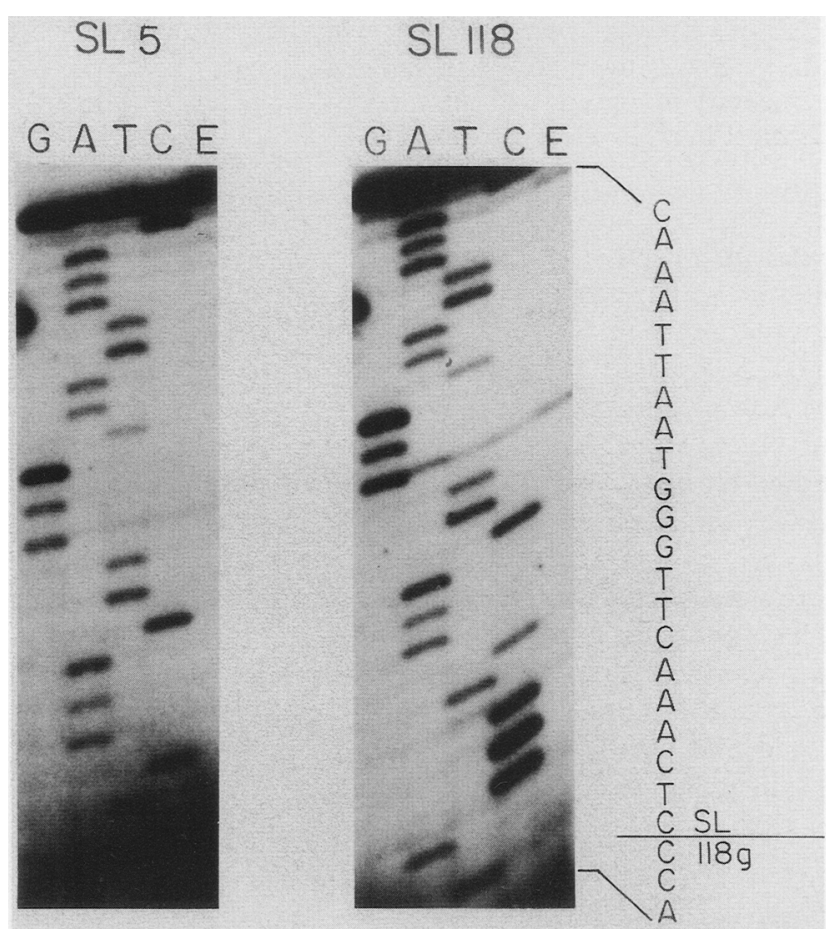

Figure 3. Primer extension sequencing of mRNAs with SL. Synthetic oligodeoxynucleotides were used to sequence the $5^{\prime}$ ends of SL5 and SL118 mRNAs. For SL5 the oligodeoxynucleotide primer is complementary to nucleotides $9-26$ of the protein coding region (the A of the ATG is position 1). For SL118 the primer is complementary to nucleotides $6-25$ of the protein coding region. (Lane $E$ ) Extended product in the absence of ddNTPs. 
ATG, but no donor site nearby. We searched the available C. elegans genomic sequences for genes with this motif. Genes that meet these criteria include glyceraldehyde-3-phosphate dehydrogenase (GAPDH Ia), ubiquitin, and the heat shock gene hsp70a (Yarbrough et al. 1987; Graham et al. 1988; Snutch et al. 1988). Therefore, we believed they would have an SL on their mRNAs. Accordingly, we synthesized oligodeoxynucleotides complementary to sequences near, but downstream of, the splice acceptor sequence for each of these genes. These oligodeoxynucleotides were used in primer extension sequencing reactions with $C$. elegans RNA. These reactions revealed that all three of these genes have SL at the 5' ends of their mRNAs (data not shown).

\section{Genomic clones corresponding to SL cDNA clones}

The three actin genes whose mRNAs carry an SL are clusterd in a $12-\mathrm{kb}$ region of chromosome $\mathrm{V}$; the act-4 gene, whose mRNA does not have an $\mathrm{SL}$, is on the $\mathrm{X}$ chromosome (Files et al. 1983; Albertson 1985). The gene encoding the SL RNA is also on chromosome V, separated by several map units from the actin cluster. We wanted to know the chromosomal locations of other genes whose mRNAs carried SL and, in particular, whether they were also located on chromosome V. Accordingly, we isolated genomic clones from an EMBL-4 library of $C$. elegans DNA that correspond to five of the SL cDNA clones. The clones were mapped to contigs in order to assign them to linkage groups (Coulson et al. 1986). Clone SL52g belongs to a contig that had been mapped to chromosome IV; the other four clones belong to contigs that have not yet been assigned to linkage groups. In addition, the ubiquitin gene is on chromosome III, GAPDH Ia on chromosome II, and hsp70a on chromosome IV (R. Hecht, pers. comm.; Graham et al. 1988; Snutch et al. 1988). Therefore, genes encoding mRNAs that acquire SL are on at least four of the six $C$. elegans linkage groups.

\section{Presence of the C. elegans SL in other organisms}

We used the C. elegans SL hybridization probe to seek a similar SL in other nematode RNAs. RNAs were isolated from: (1) C. elegans var. Bergerac /which interbreeds with $C$. elegans var. Bristol, the strain in which the SL was originally found); (2) C. briggsae (another species of Caenorhabditis); (3) Panagrellus redivivus (another free-living nematode); (4) Ascaris suum (a parasitic nematode from pigs); (5) Haemonchus contortus (a sheep parasitic nematode); and (6) Anisakis spp. (a parasitic nematode from fish). The $C$. elegans SL probe hybridizes to a broad spectrum of RNAs of different molecular weights in all of these nematodes (Fig. 4). Based on these hybridization results the SL seems well conserved in the nematodes. However, this SL probe gave no detectable signal with RNA from the trematode Schistosoma mansonii (data not shown). We also examined RNAs from distantly related organisms such as yeast, trypanosomes, Dictyostelium, Drosophila, Xenopus,

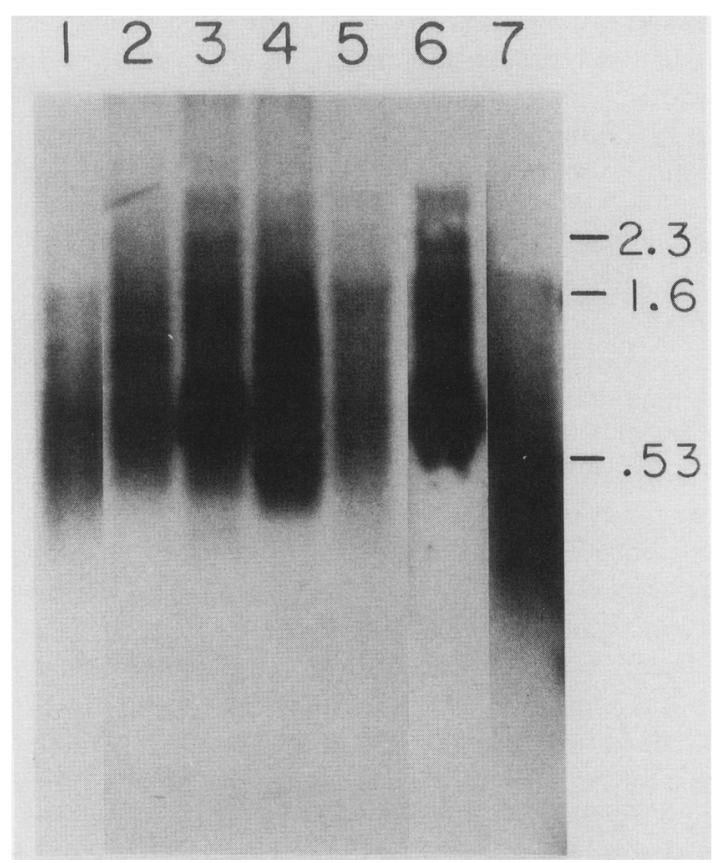

Figure 4. Analysis of the RNAs from various nematodes using Northern blots. RNAs from different nematodes was separated on a $1.5 \%$ agarose-formaldehyde gel and transferred to Zetaprobe. The blot was hybridized with an oligodeoxynucleotide complementary to the SL. (Lane 1) C. elegans var. Bristol; (lane 2) C. elegans var. Bergerac; (lane 3) C. briggsae; (lane 4) Panagrellus redivivus; (lane 5) Ascaris suum; (lane 6) Haemonchus contortus; (lane 7) Anisakis spp.

and humans. No hybridization to the SL probe occurred with these RNAs, even at reduced stringency of hybridization (data not shown).

We compared the organization of SL RNA genes in $P$. redivivus and $H$. contortus with that of $C$. elegans by screening genomic libraries. In C. elegans most of the SL RNA genes are on a $1-\mathrm{kb}$ tandem repeat (Krause and Hirsh 1987). This repeat also contains the 5S RNA gene (Nelson and Honda 1985). Of the 10,000 phage screened from a $C$. elegans genomic library, 47 hybridized to both SL and 5S probes (Table 2). No phage were isolated that contained only $5 S$ or SL genes.

In $P$. redividus, most of the clones hybridized either to the SL probe or to $5 S$ probe but not to both (Table 2). However, seven phage were identified that hybridized to both probes. In $H$. contortus no phage were found to contain both the SL and $5 S$ genes, although many were found that contain either SL or 5S. Therefore, the SL is

Table 2. Occurrence of $S L$ and $5 S$ clones in genomic libraries

\begin{tabular}{lrrc}
\hline Species & \multicolumn{1}{c}{ SL } & 5S & SL and 5S \\
\hline C. elegans & 0 & 0 & 47 \\
$P$. redivivus & 120 & 29 & 7 \\
H. contortus & 25 & 20 & 0 \\
\hline
\end{tabular}


not obligatorily linked to the 5S RNA gene in all nematodes because the average size of genomic DNA in these phage is $>12 \mathrm{~kb}$.

We sequenced clones containing SL from $P$. redivivus and $H$. contortus. The 22-nucleotide SL sequence in these nematodes is identical to C. elegans (data not shown). The rest of the SL sequence has diverged and we are presently investigating SL RNAs in these other nematodes.

\section{Discussion}

The original discovery of trans-splicing in C. elegans was based on finding the same 22-nucleotide leader sequence on mRNAs transcribed from three different actin genes. The SL probe which is complementary to the central 20 nucleotides of the 22-nucleotide sequence hybridized to other RNAs but the targets of the probe were not known (Krause and Hirsh 1987).

We have now shown that many mRNAs other than actin have an SL sequence at their $5^{\prime}$ ends. From hybrid arrest of translation experiments we estimate that 10 to $15 \%$ of the proteins are translated from SL mRNAs. This contrasts with results in trypanosomes where complete arrest of protein synthesis was observed in a similar experiment (Walder et al. 1986). In our experiment we used a rabbit reticulocyte in vitro system that reveals the products of approximately 200 of the most highly translated mRNAs. If SL serves either to enhance or to repress translation in vitro then this estimate may be either too high (enhancement) or too low (repression).

The mechanism by which hybridization to the complementary SL sequence blocks translation is not known. It has been shown that oligodeoxynucleotides complementary to the initiation codon region or to sequences $5^{\prime}$ of the initiator ATG inhibit translation in a rabbit reticulocyte in vitro system (Liebhaber et al. 1984; Blake et al. 1985). However, oligodeoxynucleotides complementary to coding sequences have no effect on translational elongation (Liebhaber et al. 1984). The heteroduplexes between the oligodeoxynucleotide and the mRNA prevent translational initiation but not elongation. Therefore, our results indicate that 10 to $15 \%$ of the mRNAs have SL at their $5^{\prime}$ ends and their translation is most likely inhibited by duplex formation.

The fact that mRNAs containing SL are a minority class in C. elegans differs strikingly from the situation in trypanosomes. Apparently all mRNAs in these protozoa receive an SL sequence (Walder et al. 1986). That only a minority class of mRNAs in C. elegans contains SL raises the question of what special feature they might share. This led us to ask whether the proteins encoded by SL mRNAs share an obvious common physiological function. This required identifying proteins in addition to actins whose mRNAs contain SL.

We used two different approaches to identify proteins in C. elegans encoded by SL mRNAs. One approach was to examine known genomic sequences upstream of the open reading frame for a splice acceptor sequence that does not have a splice donor nearby and then do primer extension sequencing of the corresponding mRNA. This strategy exploits the fact that most $C$. elegans introns are small, so that a donor site for a conventional intron should not be far upstream. Three genes with SL mRNAs (ubiquitin, hsp70a, and GAPDH Ia) were identified in this way. This strategy might also prove useful for finding genes in other organisms that acquire a spliced leader despite the presence of larger introns.

Our other approach was to make a library enriched for SL cDNAs and compare their sequences to the sequences of known genes. In this way we were able to identify 2 of 25 clones. As the sequence databases expand, particularly for C. elegans genes, we will be able to identify more of these SL clones. From the genes identified so far, actin, ubiquitin, two ribosomal proteins, hsp70a, and GAPDH Ia, no clear common physiological function emerges. One can envision roles for SL other than a common physiological function for the proteins. For example, a likely role for SL may be to regulate translation either by affecting ribosome binding or mRNA stability.

Actin genes 1, 2, and 3 reside on chromosome $\mathrm{V}$, which is also the location of the $5 S$ rDNA repeat encoding the SL RNA, although the $5 \mathrm{~S}$ repeat and the actins are far from each other on chromosome V. Nevertheless, this did raise the possibility that linkage was a prerequisite for trans-splicing. It is clear now that SL mRNAs are encoded by genes on chromosomes II, III, IV, and V. Although there are some dispersed copies of the SL RNA, no SL RNA gene has been found associated with the 12-kb actin gene cluster (Krause and Hirsh 1987). Nor was a copy of the SL RNA gene detected on the DNAs of the contigs encoding two SL mRNAs, SL5 and SL13 (S. Bektesh and B. Rosenzweig, unpubl.). This is further support for discontinuous synthesis of SL mRNAs.

Although the SL sequence is evolutionarily highly conserved, its location relative to the $5 \mathrm{~S}$ rDNA repeat is not. In C. elegans the 5S rRNA and SL RNA genes are transcribed divergently and separated by only $176 \mathrm{nu}$ cleotides (Krause and Hirsh 1987). This finding raised the possibility that their transcription is coupled and possibly regulated by cis elements. A second possibility is that the location of the SL RNA in the $5 \mathrm{~S}$ repeat is a means to insure the abundancy of the SL RNA genes. However, in $P$. redivivus and $H$. contortus, there are many copies of SL RNA genes, and they are not associated with the $5 \mathrm{~S}$ rDNA repeats. Therefore, in these organisms other factors are operating to maintain the high copy number of SL RNA genes. In addition, if transcription of $5 \mathrm{~S}$ rRNA and SL RNA is coupled, it is probably through trans rather than cis factors.

Although there does not appear to be a strongly crosshybridizing SL sequence in other taxa examined, it is possible that other organisms have an SL of different sequence. The trypanosome SL sequence is 35 nucleotides and the $C$. elegans SL only 22 nucleotides, but there are two regions of homology that extend for a total of 11 of 22 nucleotides of the C. elegans SL. However, even with reduced stringency, the $C$. elegans SL does not hybridize 
with the trypanosome SL. It is not known whether the homology is fortuitous or actually represents conservation of functionally important regions. Only further studies on the mechanisms of trans-splicing and the functions of SL will answer these questions.

\section{Materials and methods \\ RNA isolation and analysis}

Total and poly(A)+ RNAs were isolated as described previously (Cox et al. 1985). RNA from Anisakis spp. and Schistosoma mansonii was a gift from Judy Sakanari. RNA from Ascaris suum was a gift from Karen Bennett. RNA from Haemonchus contortus was a gift from George Cox. For Northern analyses, RNAs were separated on $1.5 \%$ agarose $/ 2.2 \mathrm{M}$ formaldehyde $/ 50$ mM HEPES ( $\mathrm{pH} 7.8$ ) gels and transferred to Zetaprobe (Bio-Rad) charged nylon membranes in $2 \times$ SSC. Oligodeoxynucleotide probes were treated with $\mathrm{T} 4$ polynucleotide kinase (Boehringer) by standard procedures and hybridized to filters in $6 \times$ SSC, $2 \times$ Denhardt's solution, $1 \%$ SDS, and $100 \mu \mathrm{g} / \mathrm{ml}$ of $\mathrm{tRNA}$. Hybridizations were done overnight at $2-4^{\circ} \mathrm{C}$ below the theoretical $T_{m}$ of the oligodeoxynucleotide.

\section{Probes}

The SL complementary oligodeoxynucleotide has the sequence TCAAACTTGGGTAATTAAAC. The actin oligodeoxynucleotide probe is complementary to all four actin mRNAs from nucleotides 35 to 52 of the coding region. The sequence is ACATTCCGGATCCATTGT. To prepare a 5S rRNA probe, a cloned 1-kb BamHI 5S rDNA fragment was digested with PvuI which separates 5S and SL RNA sequences (Krause and Hirsh 1987). The 695-bp BamHI-PvuI fragment was gel-purified and nick-translated with $[\alpha-32$ P]CTP.

\section{Construction of an SL-enriched cDNA library}

First-strand cDNA was synthesized using reverse transcription and priming with oligo(dT) on poly $(\mathrm{A})^{+}$RNA. The RNA was hydrolyzed with $0.25 \mathrm{~N} \mathrm{NaOH}$ for $30 \mathrm{~min}$ at $45^{\circ} \mathrm{C}$, neutralized with $0.25 \mathrm{~N} \mathrm{HCl}$ and $0.25 \mathrm{M}$ Tris- $\mathrm{HCl}(\mathrm{pH} \mathrm{7.6)}$, phenol-extracted, and ethanol-precipitated. Synthesis of second-strand cDNA was primed with a synthetic oligodeoxynucleotide identical in sequence to the spliced leader. T4 DNA polymerase was used to blunt end the double-stranded cDNA. The cDNA was methylated with EcoRI methylase, EcoRI linkers were added, and the cDNA library was cloned into the EcoRI site of pUC13.

\section{Genomic libraries}

The $C$. elegans and $P$. redivivus genomic libraries were a gift from Chris Link (Link et al. 1987). The $H$. contortus EMBL 3 library was a gift from George Cox.

\section{Primer extension sequencing of RNA}

Five nanograms of specific $\alpha^{-32} \mathrm{P}$-labeled oligodeoxynucleotide primer was annealed to $10-60 \mu \mathrm{g}$ of total RNA in a $12-\mu \mathrm{l}$ final volume containing $250 \mathrm{mM} \mathrm{KCl}, 10 \mathrm{mM}$ Tris- $\mathrm{HCl}$ (pH 8.3). The mixture was heated to $80^{\circ} \mathrm{C}$ for $3 \mathrm{~min}$ and allowed to anneal for $45 \mathrm{~min}$ at a temperature that was $5-7^{\circ} \mathrm{C}$ below the $T_{\mathrm{m}}$ of the oligodeoxynucleotide. Following annealing, $2 \mu \mathrm{l}$ of template/ primer was aliquoted to microfuge tubes containing $1 \mu l$ of either ddATP, ddGTP, ddCTP, ddTTP $(0.2-1 \mathrm{mM})$ or no ddNTPS. Then $3.3 \mu \mathrm{l}$ of reverse transcription buffer containing $24 \mathrm{~mm}$
Tris- $\mathrm{HCl}(\mathrm{pH} 8.3), 16 \mathrm{mM} \mathrm{MgCl}_{2}, 8 \mathrm{~mm}$ dithiothreitol, $0.4 \mathrm{~mm}$ dATP, $0.4 \mathrm{~mm}$ dCTP, $0.4 \mathrm{~mm}$ dTTP, $0.8 \mathrm{~mm} \mathrm{dGTP,} 100 \mu \mathrm{g} / \mathrm{ml}$ actinomycin $\mathrm{D}$, and 3-6 units of avian myeloblastosis virus reverse transcriptase were added to each sample and incubated at $50^{\circ} \mathrm{C}$ for $45 \mathrm{~min}$. Reactions were stopped by addition of $2 \mu \mathrm{l}$ of $100 \%$ formamide containing $0.3 \%$ bromphenol blue and $0.3 \%$ xylene cyanol. Samples were boiled for $3 \mathrm{~min}$ and loaded on either $8 \%$ or $10 \%$ acrylamide gels containing $8 \mathrm{M}$ urea and $0.5 \times$ TBE. Electrophoresis was at 30 watts constant power until bromphenol blue reached the bottom of the gel. Gels were dried and the products visualized by autoradiography.

\section{Hybrid arrested translation}

One microgram of poly $(\mathrm{A}){ }^{+}$RNA from C. elegans was translated in rabbit reticulocyte lysates (Promega; $30 \mu \mathrm{l}$ reaction) containing $50 \%$ lysate, $3 \mu$ l of $\left[{ }^{35} \mathrm{~S}\right]$ methionine $(1400 \mathrm{Ci} /$ mmole), and $33 \mu \mathrm{M}$ amino acids except methionine. Incubation was at $30^{\circ} \mathrm{C}$ for $30 \mathrm{~min}$. In reactions containing oligodeoxynucleotides, the RNA was annealed to the oligodeoxynucleotide prior to translation or added to the translation directly. Oligodeoxynucleotides were used at $10 \mu \mathrm{M}$ in the translation reactions. Reactions were stopped by quick-freezing in dry ice/ethanol.

\section{Two-dimensional gel electrophoresis}

Five microliters of in vitro translation products were separated essentially as described by O'Farrell (1975). Electrophoresis in the first dimension was in isoelectrofocusing tube gels and the second dimension was in $10 \%$ SDS-polyacrylamide gels.

\section{Acknowledgments}

We thank George Cox, Chris Link, Karen Bennett, Judy Sakanari, and Jim McKerro for generously providing materials used in these experiments. We also thank Alan Coulson for contig mapping. We are grateful for the technical assistance of Brad Rosenzweig, Donna Krzemien, and Lydia Hurt. This work was supported by a grant from the U.S. Public Health Service No. GM37823.

\section{References}

Albertson, D.G. 1985. Mapping muscle protein genes by in situ hybridization using biotin-labeled probes. $E M B O /$. 4: 24932498.

Bektesh, S.L. and D. Hirsh. 1988. C. elegans mRNAs acquire a spliced leader through a trans-splicing mechanism. Nucleic Acids Res. 16: 5692.

Blake, K.R., A. Murakami, and P.S. Miller. 1985. Inhibition of rabbit globin mRNA translation by sequence-specific oligodeoxyribonucleotides. Biochemistry 24: 6132-6138.

Coulson, A., J. Sulston, S. Brenner, and J. Karn. 1986. Toward a physical map of the genome of the nematode Caenorhabditis elegans. Proc. Natl. Acad. Sci. 83: 7821-7825.

Cox, G.N., S. Carr, J.M. Kramer, and D. Hirsh. 1985. Genetic mapping of $C$. elegans collagen genes using DNA polymorphisms as phenotypic markers. Genetics 109: 513-528.

Files, J., S. Carr, and D. Hirsh. 1983. Actin gene family of $C$ elegans. J. Mol. Biol. 164: 355-375.

Graham, R.W., K. Van Doren, S. Bektesh, and E.P.M. Candido. 1988. Maturation of the major ubiquitin gene transcript in Caenorhabditis elegans involves the acquisition of a transspliced leader. J. Biol. Chem. 263: 10415-10419. 
Krause, M. and D. Hirsh. 1987. A trans-spliced leader sequence on actin mRNA in C. elegans. Cell 49: 753-761.

Liebhaber, S.A., F.E. Cash, and S.H. Shakin. 1984. Translationally associated helix-destabilizing activity in rabbit reticulocyte lysate. I. Biol. Chem. 259: 15597-15601.

Link, C.D., J. Graf-Whitsel, and W.B. Wood. 1987. Isolation and characterization of a nematode transposable element from Panagrellus redivivus. Proc. Natl. Acad. Sci. 84: 53255329.

Nelson, D.W. and B.M. Honda. 1985. Genes coding for 5S ribosomal RNA of the nematode Caenorhabditis elegans. Gene 38: 245-251.

O'Farrell, P.H. 1975. High resolution two-dimensional electrophoresis of proteins. J. Biol. Chem. 250: 4007-4021.

Snutch, T.P., M.F.P. Heschl, and D.L. Baillie. 1988. The Caenorhabditis elegans HSP70 gene family: A molecular genetic characterization. Gene (in press).

Spieth, J., K. Denison, S. Kirtland, J. Cane, and T. Blumenthal. 1985. The C. elegans vitellogenin genes: Short sequence repeats in the promoter regions and homology to the vertebrate genes. Nucleic Acids Res. 13: 5283-5295.

Walder, J.A., P.S. Eder, D.M. Engman, S.T. Brentano, R.Y. Walder, D.S. Knutzon, D.M. Dorfman, and J.E. Donelson. 1986. The 35-nucleotide spliced leader sequence is common to all trypanosome messenger RNAs. Science 233: 569-571.

Yarbrough, P.O., M.A. Hayden, L.A. Dunn, P.S. Vermersch, M.R. Klass, and R.M. Hecht. 1987. The glyceraldehyde-3phosphate dehydrogenase gene family in the nematode Caenorhabditis elegans: Isolation and characterization of one of the genes. Biochim. Biophys. Acta 908: 21-33. 


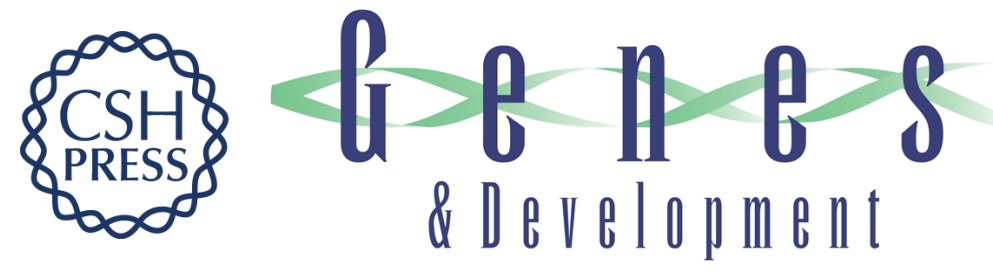

\section{Presence of the Caenorhabditis elegans spliced leader on different mRNAs and in different genera of nematodes.}

S Bektesh, K Van Doren and D Hirsh

Genes Dev. 1988, 2:

Access the most recent version at doi:10.1101/gad.2.10.1277

References This article cites 15 articles, 7 of which can be accessed free at:

http://genesdev.cshlp.org/content/2/10/1277.full.html\#ref-list-1

License

Email Alerting

Service

Receive free email alerts when new articles cite this article - sign up in the box at the top right corner of the article or click here.

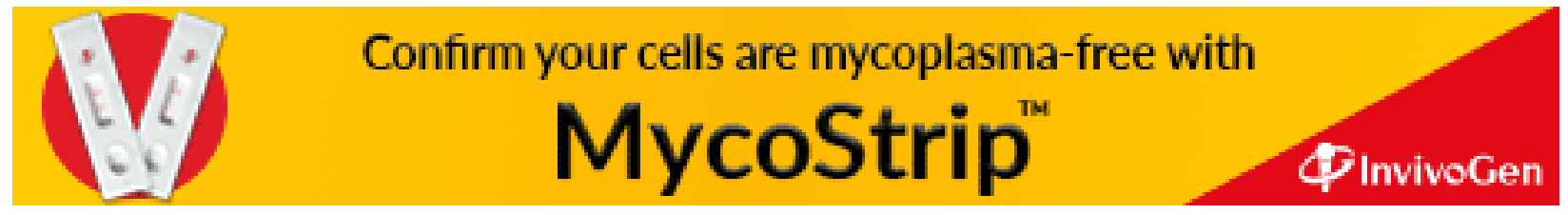

